of lead. Data from the Ministry of Agriculture, Fisheries, and Food, ${ }^{7}{ }^{8}$ however, suggest that there has been a substantial reduction in lead in most foodstuffs since 1970, and the mean dietary intakes of many foodstuffs have changed. ${ }^{9}{ }^{10}$ These data have led to estimates of daily lead intake from food ranging from about $200 \mu \mathrm{g} /$ day per adult in $1970-2^{7}$ to about $100 \mu \mathrm{g} /$ day per adult towards the end of the 1970 s. $^{8}$ While these estimates are crude, the increase in the use of frozen foodstuffs and the fall in the use of tinned foods, together with improved canning methods and other changes in the food industry, must have led to substantial reductions in lead intake from dietary sources.

An association exists between the hardness of domestic water and blood lead concentrations, and it has been suggested that hard water, even in the absence of water lead, may lower the absorption of lead from other sources." Recent surveys carried out (surveys 7 and 8; P C Elwood $e t$ al, unpublished observations) represent the first phase of longitudinal studies of the effect on blood lead concentrations in residents of hardening soft plumbosolvent water in two areas. The changes in blood lead concentrations that the surveys reported here suggest occurred during a period when no changes were made in the water supply and show the need for controlled and carefully designed studies to evaluate any measure aimed at reducing blood lead concentrations. Indeed, in view of the fall in blood lead concentrations detected during a period in which no appreciable reduction occurred in the lead content of petrol it may well prove difficult to detect any effect on blood lead concentrations of lowering exposure to environmental lead in this way.

I am grateful to the many people who played a part in these surveys, in particular Dr C Toothill, Dr P Broughton, and Dr H T Delves, of the Supra-Regional Assay Service lead laboratories; the chemists and others in the laboratories of the Welsh Water Authority; and Dr M Morton, of Tenovus Institute, Cardiff.

\section{References}

${ }^{1}$ Elwood PC, St Leger AS, Morton M. Dependence of blood lead on domestic water lead. Lancet 1976; : 1295.

${ }^{2}$ Thomas HF, Moore F, Welsby E, Elwood PC, Firth JNM. The hazard of old lead mines in Wales. British fournal of Preventive and Social Medicine $1977 ; 31: 265-8$.

3 Thomas HF, Elwood PC, Welsby E, St Leger AS. Relationship of blood lead in women and children to domestic water lead. Nature 1979;282 712-3.

${ }^{4}$ Elwood PC, Gallacher J, Toothill C. Lead in petrol. Br Med $\mathcal{f} 1982$;284: 1189.

${ }^{5}$ Center for Disease Control. Blood lead levels in the US population. $M M W R 1982$ Mar $31: 132-4$.

- Working Party on Lead in the Environment. Lead and health. Report. London: HMSO, 1980.

${ }^{7}$ Ministry of Agriculture, Fisheries, and Food. Survey of lead in food. London: HMSO, 1975.

${ }^{8}$ Walters B, Sherlock J. Studies on the dietary intake of heavy metals. International conference on heavy metals in the environment, Amsterdam, 1981. London: HMSO, 1982:506-12.

${ }^{9}$ Ministry of Agriculture, Fisheries, and Food. Household food consumption and expenditure 1970. Annual report of the National Food Survey Council. London: HMSO, 1973:68-73.

${ }^{10}$ Ministry of Agriculture, Fisheries, and Food. Household food consumption and expenditure 1979. Annual report of the National Food Survey Council. London: HMSO, $1981: 30-2$.

11 Thomas HF, Elwood PC, Toothill C, Morton M. Blood and water lead in a hard water area. Lancet $1981 ; \mathrm{i}: 1047-8$.

(Accepted 8 February 1983)

\title{
Use of the "Scotchcast boot" in treating diabetic foot ulcers
}

\author{
A C BURDEN, G R JONES, R JONES, R L BLANDFORD
}

The pathogenesis of diabetic foot ulceration includes peripheral and autonomic neuropathy, vascular abnormalities, infection, and trauma. Healing is helped by reducing pressure on the affected foot in bed or with a plaster of Paris cast with a window cut out over the lesion. ${ }^{1}$ These casts are, however, heavy and fragile when wet, needing frequent reapplication. We investigated the use of a Scotchcast (3M UK Ltd, Loughborough, Leicestershire) as a substitute for plaster of Paris because of its lightness and high integral strength.

Diabetic Unit, Leicester General Hospital, Leicester LE5 4PW

A C BURDEN, MD, MRCP, consultant physician

G R JONES, MB, MRCP, senior registrar

R JONES, SRN, plaster room sister

R L BLANDFORD, $M B, M R C P$, senior registrar

Correspondence to: Dr G R Jones.

\section{Patients and methods}

All 58 patients presenting to the diabetic clinic at this hospital with foot ulceration between February 1979 and February 1982 were studied. After vascular assessment 18 patients were excluded because they had operable disease. The remaining 40 patients formed the study population. Of these, 11 had distal vessel disease, typified by absent pulses below the femoral arteries; the other 29 had palpable popliteal pulses and at least either a dorsalis pedis or posterior tibial pulse present. Twenty seven patients had solitary lesions on the sole, six solitary lesions on the heel (fig 1), five lesions on both the sole and the toe, and two combined heel and sole lesions.

Optimum diabetic control was achieved in these patients, and if infection was evident broad spectrum antibiotics were given intravenously for five days and subsequently by mouth for up to three months. Ulcers with large areas of necrosis were surgically debrided. Wounds were dressed either with non-stick dressings (Melolin; Smith and Nephew Ltd, Birmingham) after local toilet or packed with dilute hypochlorite solution (Milton) and ribbon gauze. A Scotchcast boot was fashioned with a window cut out over the ulcer to allow dressings to be renewed; the boot was changed each month. Dressings were reapplied as required, and patients were regularly supervised at the foot clinic.

When the ulcers had healed "space shoes" were fitted (Lane Orthopaedics Ltd, Northampton). These are high volume shoes made with 
a soft leather upper in a single piece and a composite sole; they have a premoulded polystyrene insert sole of multiple construction which may be raised as necessary.

\section{APPLICATION OF SCOTCHCAST BOOT}

A well fitting $100 \%$ cotton stockinette sock (C \& H Coverdale, Leicester) was placed on the foot. A $0.6 \mathrm{~mm}$ felt sole ( $R \mathrm{R}$ Whitehead Bros Ltd, Oldham) with a precut window and an ankle felt were held in place with a $15 \mathrm{~cm}$ water repellent padding bandage (Soffban; Smith \& Nephew, Birmingham) the ulcer site being marked (fig 2). Two $5 \mathrm{~cm}$ or $7.6 \mathrm{~cm}$ Scotchcast bandages ( $3 \mathrm{M} \mathrm{UK}$ ) were used to make the cast by covering the padded area from the ankle to the toes in the shape of a boot (fig 3). The cast was then trimmed when set leaving a cut away section at the ankle to give full movement. The toes were left free and a window was cut. The padding and stockinette formed a soft edge around the cast and were held in place with $5 \mathrm{~cm}$ wide elastoplast (fig 4). The window area was sealed with Blendeim tape (3M UK) to provide a waterproof edge. The patient was then fitted with an open toed "walking shoe" ( 3 M UK) (fig 5) and was allowed to bear weight after 30 minutes.

\section{Results}

Of the 40 patients treated, the lesions healed in 35 within a mean of three months (range 1-8 months). The longest time to healing was in those patients with absent distal pulses and heel lesions (table). Five patients had lesions which failed to heal. In three of these

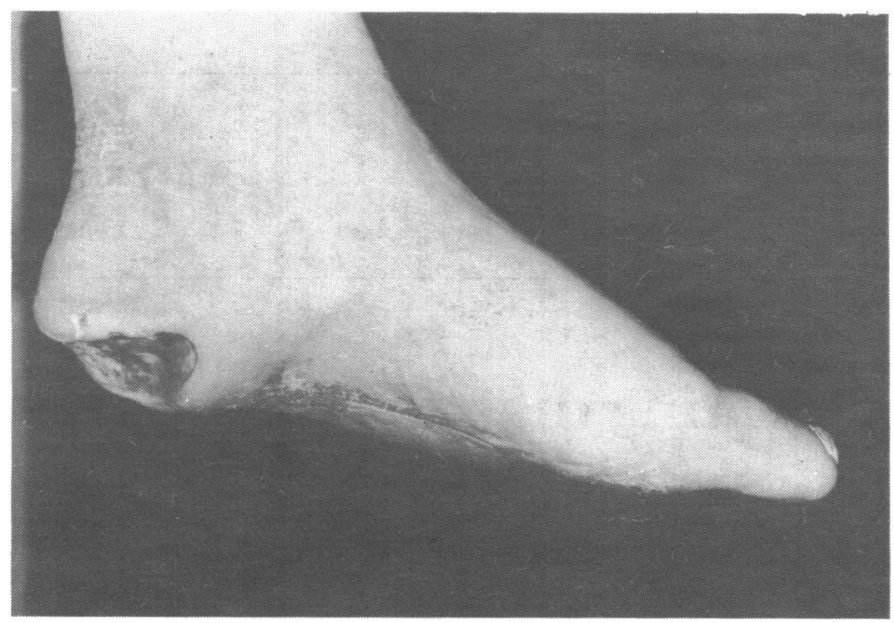

FIG 1-Foot with diabetic ulcer on the heel.

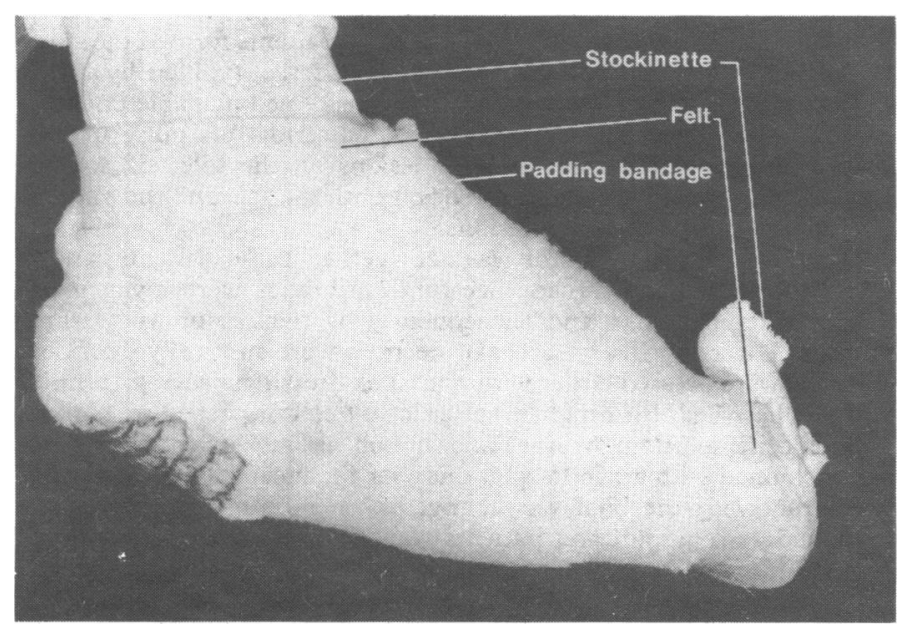

FIG 2-Foot covered with "soft" dressings.

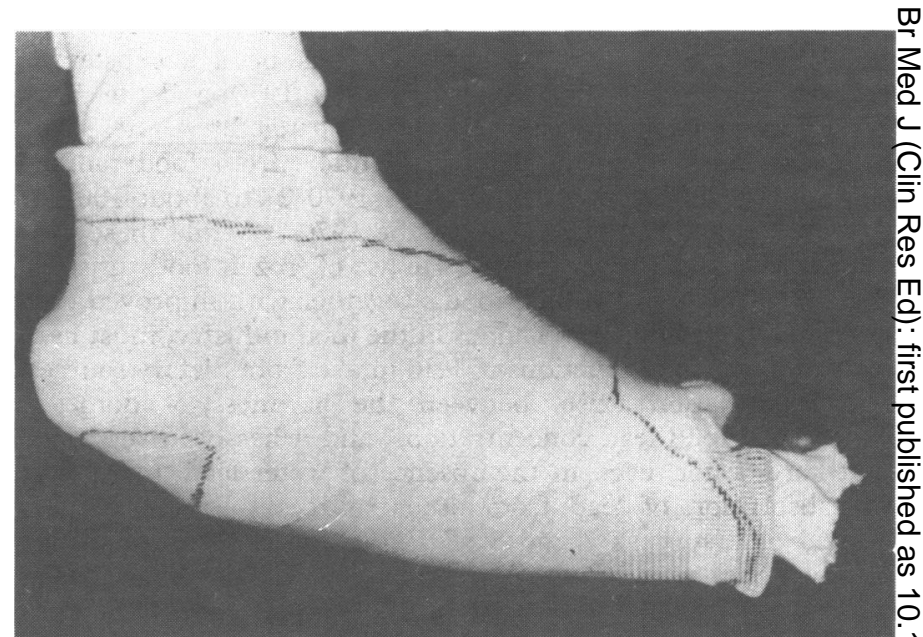

FIG 3-"Scotchcast" bandage in place over foot ready for trimming.
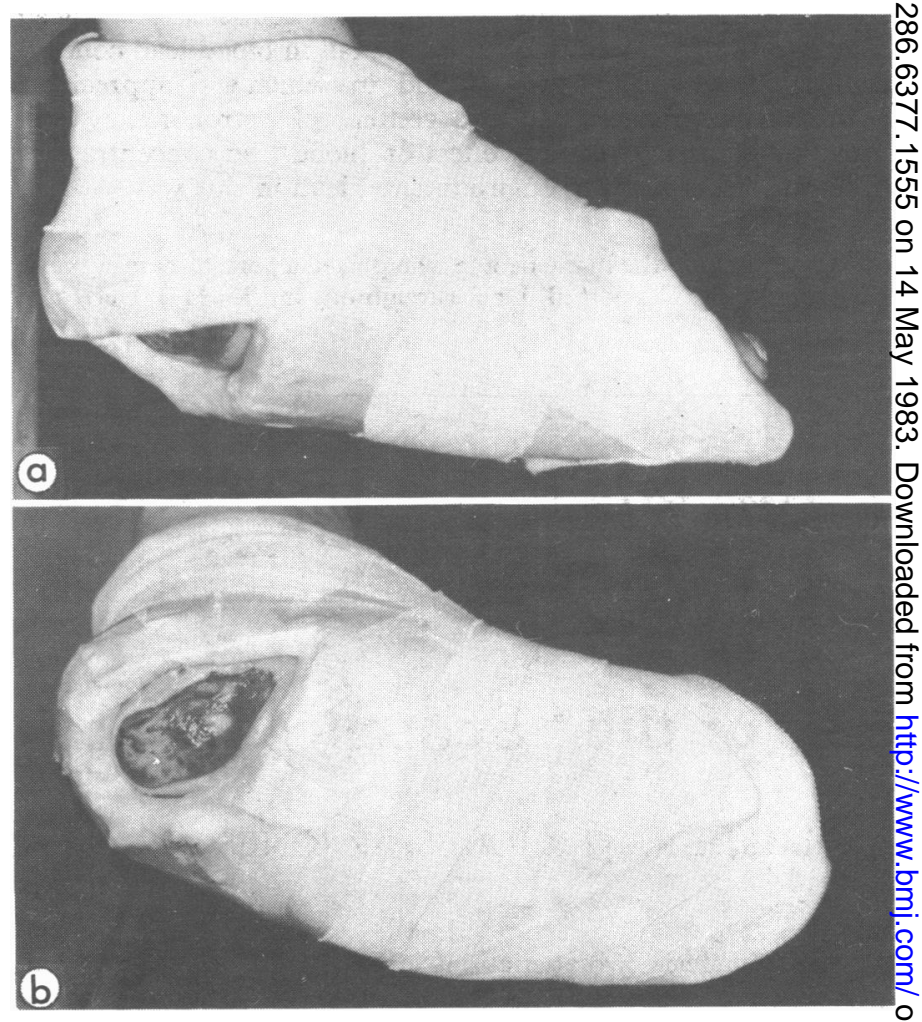

FIG 4-Trimmed boot with soft dressings pulled over cast and held with elastoplast $(a)$ from the side and $(b)$ from underneath showing ulcer edge clear of cast.

patients lesions occurred at the start of the study owing to poor finishing of the cast around the ankle; in two patients the lesions healed after reapplication of the boot and in one after 46 days' bed rest. Onero woman stopped treatment for cosmetic reasons, but her lesion healed after she had agreed to further treatment and the boot had beenco reapplied. The fifth patient had severe vascular disease and needed an amputation above the knee after nine months, having refused amputa- $\overline{0}-\overline{0}$ tion initially.

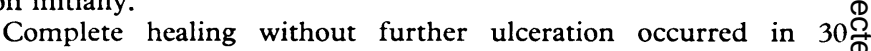
patients (minimum follow up nine months). In five patients whose@ lesions healed initially reulceration occurred; with further treatment $\bar{O}$ with the Scotchcast boot all the lesions rehealed. Three of these patients are being managed in "space shoes" and two need to wear theo응 Scotchcast boot permanently.

All the patients treated were fully ambulant and those workingo․ㅡㄹ continued except for one employed as a gardneer and two of four. employed as drivers who changed to desk jobs. 


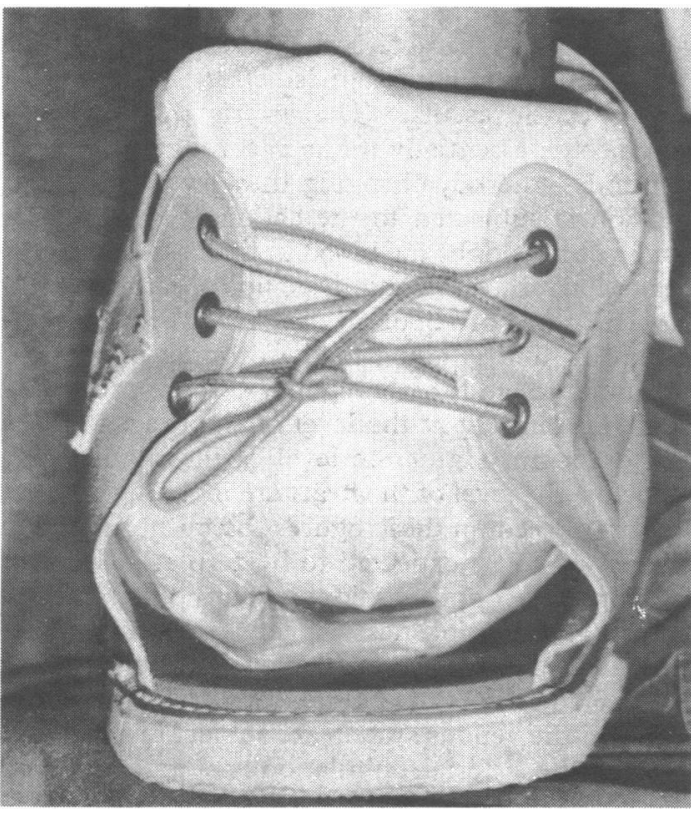

FIG 5-Patient's foot while standing with walking sandal on and ulcer undressed to show absence of weight bearing by affected area.

\section{Comment}

Treatment with the Scotchcast boot allows the diabetic patient with foot ulceration to be managed primarily as an outpatient and to continue to be a useful member of the com-
Time taken for diabetic foot ulcers to heal when treated with the Scotchcast boot

\begin{tabular}{cccc}
\hline & & \multicolumn{2}{c}{ No of patients } \\
\cline { 3 - 4 } $\begin{array}{c}\text { Time treated } \\
\text { (months) }\end{array}$ & No healed & With heel lesions & With distal vessel disease \\
\hline 1 & 11 & 0 & 0 \\
2 & 6 & 1 & 0 \\
3 & 6 & 0 & 3 \\
4 & 4 & 2 & 2 \\
5 & 3 & 1 & 0 \\
6 & 1 & 1 & 1 \\
7 & 1 & 0 & 3 \\
8 & 3 & 3 & \\
\end{tabular}

munity. Provided that careful attention is given to footwear the patient is likely to have no problems, although during the rest of his life he will require regular chiropody and constant attention to footwear: it is likely that the three patients who had further ulceration which rehealed after reapplication of the boot had worn ordinary shoes.

The treatment is relatively cheap because it avoids expensive inpatient care. The technique does, however, need the skills of a highly trained plaster technician or nurse. The disadvantages of the Scotchcast boot compared with the more conventional plaster of Paris cast is that the edges are sharp and, if applied without care, may damage otherwise healthy skin.

We thank Mrs Neera Sharma for secretarial help and Miss Lizzie Keis, medical photographer, Leicester General Hospital.

\section{Reference}

1 Wagner FW Jr. Algorithms of diabetic foot care. In: Levin MK, O'Neal LW, eds. The diabetic foot. St Louis: C V Mosby, 1983:291-302.

(Accepted 25 February 1983)

\section{Aviation Medicine}

\section{Acceleration}

\section{I: Long duration acceleration}

\section{F JOHN MILLS, RICHARD M HARDING}

\begin{abstract}
"Man regularly performs the greatest of all experiments in gravitational physiology at least once a day when he rises from his bed."1
\end{abstract}

Terrestrial life exposes us all to the acceleration of normal gravity for a lifetime. Flight and space exploration have, however, exposed man to far greater accelerations which can be tolerated for only much shorter periods. The adverse physiological effects

RAF Institute of Aviation Medicine, Farnborough, Hants F JOHN MILLS, MA, MB, squadron leader RICHARD M HARDING, MB, DAVMED, squadron leader

Correspondence to: Dr F John Mills, Janssen Pharmaceutical Ltd, Marlow, Bucks. of these accelerations are fundamental problems in aviation medicine.

Acceleration is the rate of change of velocity with time and occurs when the speed or direction of motion of a body alters. The magnitude ( $\mathrm{n} G$ ) of an acceleration is conveniently expressed in multiples $(n)$ of the acceleration due to gravity $(g)$, which we sense as weight. Thus a military aircraft exposes its pilot to an acceleration of six times that of gravity when "pulling" $6 G$, and his weight will consequently have increased sixfold. The pilot's physiological responses to this acceleration will be determined, firstly, by its magnitude and, secondly, by the duration and direction of its action. Duration is classified as either long or short, the time division between the two being set at one second. Though this separation appears to be quite arbitrary, in practice it is of great functional significance because excessive accelerations of short duration usually result in pathological changes, whereas those of long duration have 